\title{
Functional hemizygosity in the human genome: direct estimate from twelve erythrocyte enzyme loci
}

\author{
H.W.Mohrenweiser* \\ Department of Human Genetics, University of Michigan Medical School, Ann Arbor, MI 48109-0618, USA
}

\begin{abstract}
Summary. Cord blood samples from 2020 unrelated newborns were screened for levels of enzyme activity for twelve enzymes. The level of enzymatic activity for 100 determinations were consistent with the existence of an enzyme-deficiency allele. The frequency of deficiency alleles in the Black population (0.0071) was four times higher (after removal of the G6PD*A $\mathrm{A}^{-}$variant) than in the Caucasian sample $(0.0016)$. These frequencies are approximately double the frequency of rare electrophoretic mobility variants at similar loci in the same population. Given the number of functionally important loci in the human genome, these enzyme deficiency variants could constitute a significant health burden.
\end{abstract}

\section{Introduction}

Increasing evidence is accumulating that the genome of each individual may be functionally hemizygous at from several to many autosomal loci, in addition to the loci located on the sex chromosome. That is, one member of the allelic pair at an autosomal locus is either absent (molecular hemizygosity) or is unable to direct the synthesis of functional gene product (biochemical hemizygosity). The level of hemizygosity in the human genome has a direct impact on the frequency of both genetic disease and reproductive failure (Carter 1977, 1982; Neel 1979; Vogel 1984; Costa et al. 1985). Hemizygosity also has a direct effect on the estimated health cost of mutational damage in that a functionally significant mutation at a hemizygous locus would appear to be inherited as a dominant trait and would be of significance in the first generation (Mohrenweiser 1983; Searle and Edwards 1986).

Examples of hemizygosity that have received recent attention are the several heritable tumors that are associated with a predisposing event involving the apparent absence of genetic material (Cavence et al. 1986; Seizinger et al. 1986). That is, the individual is apparently hemizygous at a locus associated with tumor development and therefore a single somatic event is sufficient to initiate tumorogenesis. Molecular hemizygosity in the genome, identified with Southern blotting techniques and not associated with disease conditions, has also been identified. These known hemizygous segments include regions adjacent to several defined genes (Bell et al. 1980; Rotwein et al. 1983), variation in the number of copies of genes (Erickson and Schmickel 1985), and variation in the copy number of re-

\footnotetext{
* Current address and address for offprint requests: Biomedical Sciences Division, L-452, Lawrence Livermore National Laboratory, Livermore, CA 94550, USA
}

petitive elements (Jeffrey et al. 1985). Molecular studies of a series of genetic diseases outline the range of events, considered as "point mutations", which at the physiological/metabolic level of cellular function appear to be null alleles. These events range from the complete or partial deletion of a gene (Monaco et al. 1986; Rozen et al. 1985; Spritz and Forget 1983; Yang et al. 1984) to seemingly innocuous base substitutions (Busslinger et al. 1981; Daar et al. 1986; Spritz et al. 1981). Although the frequency of hemizygosity at any single locus associated with a genetic disease or a genetic predisposition to a disease appears to be small, it would appear that the total hemizygosity in the genome may be significant when summed across the estimated 50-100,000 expressed loci of the human genome (Office of Technology Assessment 1986).

Within the context of the development of a program to study the germinal mutation rate in human populations (Neel et al. 1987), we have now examined erythrocyte samples from 2020 unrelated newborns, including those from previous reports (Mohrenweiser 1981, 1983), for the presence of a level of enzyme activity consistent with the existence of an enzyme deficiency allele at twelve erythrocyte enzyme loci. Data from similar studies in other populations will be reviewed in order to estimate the apparent level of detectable hemizygosity as manifested by a specific reduction in enzyme activity for a set of loci encoding enzyme proteins. The data will be contrasted with the frequency of rare electrophoretic mobility variants in the same populations.

\section{Materials and methods}

Umbilical cord blood samples were obtained from newborns at the University of Michigan Women's Hospital. Informed consent and blood samples were obtained from parents; the samples were stored in liquid nitrogen (Neel et al. 1979). Adenylate kinase (AK, EC 2.7.4.3); aspartate aminotransferase (GOTS, EC 2.3.1.1); enolase (ENO, EC 1.2.1.11); phosphoglyceromutase (DPGM, EC 2.7.5.3); glyceraldehyde3-phosphate dehydrogenase (GAPD, EC 1.2.1.12); glucosephosphate isomerase (GPI, EC 5.3.1.9); glucose-6-phosphate dehydrogenase (G6PD, EC 1.1.1.49); lactate dehydrogenase (LDH-B, EC 1.1.1.27); malate dehydrogenase (MDH, EC 1.1.1.37); phosphoglycerate kinase (PGK, EC 2.7.2.3); pyruvate kinase ( $\mathrm{PK}, \mathrm{EC} 2.7 .1 .40$ ); and triosephosphate isomerase (TPI, EC 5.3.1.1) assays were performed as described by Fielek and Mohrenweiser (1979), Mohrenweiser (1983), and Mohrenweiser and Fielek (1982). The stability characteristics of each enzyme as well as the influence of reticulocyte per- 
Table 1. Distribution and frequency of erythrocyte-enzyme-deficiency variants among loci in unselected newborns

\begin{tabular}{|c|c|c|c|c|c|c|c|c|c|c|c|}
\hline \multirow[t]{2}{*}{ Enzyme } & \multicolumn{10}{|c|}{ Number of occurrences } & \multirow{2}{*}{$\begin{array}{l}\text { Total }^{\mathrm{b}} \\
\text { variants/ } \\
\text { deter- } \\
\text { mination }\end{array}$} \\
\hline & \multicolumn{5}{|c|}{ Normal activity (\%) } & \multicolumn{5}{|c|}{ Normal activity (\%) } & \\
\hline ENO & 2 & 3 & 0 & 1 & $6 / 1094$ & 1 & 0 & 0 & 0 & $1 / 85$ & $10 / 1246$ \\
\hline GAPDH & 0 & 0 & 0 & 0 & $0 / 1035$ & 0 & 0 & 0 & 0 & $0 / 84$ & $0 / 1183$ \\
\hline GOTS & 0 & 0 & 1 & 1 & $2 / 1592$ & 0 & 0 & 0 & 1 & $1 / 161$ & $3 / 1854$ \\
\hline GPI & 2 & 1 & 0 & 1 & $4 / 1712$ & 0 & 0 & 0 & 0 & $0 / 168$ & $4 / 1986$ \\
\hline $\mathrm{LDH}$ & 0 & 0 & 0 & 0 & $0 / 1736$ & 0 & 0 & 0 & 0 & $0 / 170$ & $0 / 2013$ \\
\hline TPI & 2 & 1 & 3 & 3 & $9 / 1713$ & 1 & 0 & 1 & 5 & $7 / 168$ & $17 / 1987$ \\
\hline G6PD (Female) & 6 & 3 & 1 & 0 & $10 / 821$ & 4 & 2 & 0 & 2 & $8 / 71$ & $19 / 952$ \\
\hline G6PD (Male) & 0 & 0 & 2 & 1 & $3 / 908$ & 9 & 3 & 0 & 0 & $12 / 97$ & $16 / 1052$ \\
\hline G6PD (Total) & & & & & $13^{c} / 1729$ & & & & & $20^{d} / 168$ & $35^{\mathrm{c}, \mathrm{d}} / 2004$ \\
\hline Total & & & & & $57 / 18,620$ & & & & & $34 / 1767$ & $100 / 21,536$ \\
\hline
\end{tabular}

a Activity for sex linked trait

b Total includes about 100 probands that could not be assigned to the other two ethnic groups

c Includes one mobility variant, G6PD*CAA1

d Includes 11 variants with $\mathrm{G} 6 \mathrm{PD}^{*} \mathrm{~A}^{-}$mobility

centage and mean cell age on the level of enzyme activity in both adult and cord blood samples have been described (Mohrenweiser et al. 1981). Only the first-born child in any family has been included in the current sample, in contrast to the report on mutation rates in this population by Neel et al. (1987) where, with the exception of identical twins, all newborns were included. Approximately 3\%-4\% of the probands were considered premature (birth weight $<2000 \mathrm{~g}$ ) or exhibited a congenital defect (Neel and Mohrenweiser 1984).

\section{Results}

Functional null or enzyme-deficiency variants were defined by a level of enzymatic activity that was less than $65 \%$ of the normal or control mean activity and concurrently, a value at least 3 standard deviations ( $S D$ ) below the population mean (Mohrenweiser 1981). The latter constraint has proven to be redundant in that the coefficient of variation among individuals within the newborn or the adult population is less than $12 \%$ for each of the twelve enzymes included in the study and therefore $65 \%$ of control is always more than three SDs from the mean (Mohrenweiser 1983). In addition, for the reduced activity to be classified as the result of an enzyme-deficiency allele, the activity of other enzymes assayed in this individual sample must be within the normal range. Thus, abnormal results associated with generalized hemoglobinopathies or other traits not involving a specific enzyme locus would be excluded from further consideration. This requirement of a normal level of activity for other erythrocyte enzymes also serves as a control for sample quality. Only a single example of a proband with two deficiency alleles was observed. This male child in- herited the TPI deficiency allele from the father and the G6PDA allele from his mother.

The results from screening samples from 1740 Caucasian and 172 Black unrelated newborns are shown in Table 1 . The total group includes additional individuals from other races $(1 \%)$ as well as individuals of mixed or unknown racial origins $(4 \%)$. In 100 of the 21,536 determinations, the level of enzymatic activity was consistent with the existence of an enzyme-deficiency variant. A genetic basis for the reduced activity was confirmed for each variant by the detection of a reduced level of enzyme activity in erythrocytes from one of the parents. Fifty-seven of the variants were identified among 18,620 determinations ( 3.1 variants per 1000 determinations) from Caucasian newborns while 34 variants were detected among 1767 determinations (19.2 variants per 1000 determinations) from Black newborns.

Enzyme-deficiency variants were detected in this study at nine of the twelve loci screened. Deficiencies at the other three loci have been identified in other studies and have been reported in the clinical literature. An $\mathrm{LDHB}$ null variant has been identified as a polymorphism in a Central American Indian population (Tanis et al. 1977; Mohrenweiser and Novotny 1982); while deficiencies of PGK and GAPDH as well as $\mathrm{LDH}$ have been reported, although they are less frequent than many of the other enzymopathies (Beutler 1978; Kahn et al. 1979). Thus, it is probable that the absence of deficiency variants at these three loci, in this study, reflects the frequencies of the deficiency alleles in the population studied in Ann Arbor rather than a failure of the analytical procedures.

The range of residual activity in the probands (with the exception of males with G6PD deficiency) ranged from $44 \%-$ $64 \%$ of normal and from 3.3 to $5.4 S D$ s below the mean. In all 
families, one parent had a level of enzyme activity consistent with the profile observed in the proband. The affected parents were evenly distributed between mothers and fathers. Thus, the marked reduction in enzyme activity had characteristics of a recessively (or sex-linked, in the case of G6PD deficiency) inherited genetic trait. The specificity of the reduction, that is, restriction to a specific enzyme, and codominant inheritance would be consistent with the existence of a molecular lesion involving the structural gene or the immediate flanking regions for the enzyme exhibiting the reduced activity. In general, genetic variation that does not involve the structural locus would not usually be inherited as a codominant trait, as are the nonsex-linked traits observed in this study.

The frequency of enzyme-deficiency alleles in the Caucasian sample is 0.00161 while the frequency in the Black sample is about six times higher, namely 0.01010 . The relatively high frequency of G6PD deficiencies in Blacks and PK deficiencies in Caucasians is consistent with the clinical data on enzymopathies and the frequency of the G6PG*A variant in the Black population (Beutler 1979; Motulsky and Yoshida 1969). Of the 20 G6PD deficiencies in Blacks, 11 were associated with the electrophoretically detectable $\mathrm{A}^{-}$allele. Excluding these 11 variants from the deficiency class reduces the frequency of such variants to 0.0071 in the Black group, a frequency still more than four times the frequency in the Caucasian group. One of the G6PD deficiencies in the Caucasian group was associated with a variant with $\mathrm{C}$-like electrophoretic mobility. With the exception of the above mentioned G6PD mobility variants, none of the other deficiency variants were associated with an identifiable alteration in electrophoretic mobility. The existence of a weakly staining mobility variant would be consistent with the deficiency being associated with an unstable enzyme molecule, as is known for the G6PD* $\mathrm{A}^{-}$variant. The absence of detectable mobility variation does not exclude an unstable enzyme molecule as the cause of the deficiency. The interchanged amino acids may have had similar charges or the residual enzyme activity may have been too low to be detected following electrophoresis, especially in the heterozygote individual. Failure to produce a recognizable gene product or the existence of an inactive enzyme subunit are other possible explanations for the absence of detectable functional gene product.

As previously noted in preliminary reports from this newborn screen, the high frequency of the TPI-deficiency allele, especially among Blacks, was surprising (Mohrenweiser 1983; Mohrenweiser and Fielek 1982). Reports of homozygosity for TPI deficiency in the clinical literature are relatively rare with only about thirty reported cases in the world including only four individuals in three families in the U.S. (Maquat et al. 1985; Mohrenweiser and Fielek 1982; Rosa et al. 1985). This contrasts with the expected frequency of at least 1 in 2000 Black newborns, given that the deficiency allele frequency is 0.023 in this population. No homozygous deficient probands were observed in this study, as expected given the number of Black newborns screened. Because of the severity of the symptoms, the homozygous deficient individuals should be observed in clinical studies if they survive to birth. Studies of TPI-deficient mice indicate that homozygosity for several different TPI null alleles is apparently an embryo lethal condition, in that no homozygous deficient animals are observed (Charles and Pretsch 1987). Given the apparent lethality of the homozygous condition and the calculation that TPI is the least rate-limiting step in glycolysis (Albery and Knowles
1976), it is difficult to identify a mechanism for the maintenance of this allele frequency.

A direct comparison of the relative frequency of deficiency and mobility variants can be made at nine loci (excluding DPGM, PK, and GAPD, which were not studied for mobility variants). In the Caucasian sample, the frequency of alleles for enzyme deficiencies at these nine loci was 0.00169 compared to an allele frequency of 0.00083 (35 variants/42,111 alleles) for rare mobility variants at the same loci (Mohrenweiser et al. 1987). Similar figures in the Black sample were 0.0078 for deficiency alleles (excluding $\mathrm{G} \mathrm{PD}^{*} \mathrm{~A}^{-}$) and 0.00088 (3 variants/3395 alleles) for rare electrophoretic mobility alleles (G6PD*A is a polymorphic variant and therefore is excluded as a rare variant in the Black sample). Data are available on the frequency of alleles for rare electrophoretic mobility variants at forty erythrocyte enzyme loci in these populations, the frequencies being 0.00056 for Caucasians and 0.00159 for Blacks. Thus, the frequency of deficiency variants was $100 \%-250 \%$ greater than the frequency of rare electrophoretic mobility variants, irrespective of the data base of electrophoretic mobility variants used for the comparison.

\section{Discussion}

Three other studies of human populations have employed similar techniques to screen for enzyme-deficiency alleles. Eber et al. (1984) and Krietsch et al. (1977) studying only 5 erythrocyte enzymes, reported seven variants in about 3000 individuals ( 0.5 variants/1000 determinations) in Germany. The null-allele frequency (recalculated from their data using $65 \%$ of normal as the definition for a deficiency variant) is 0.00028 . They also identified additional individuals with lesser degrees of activity reduction, which are not included in the above frequency calculation but which had characteristics consistent with a heritable genetic trait. Satoh et al. (1983) in Japan, studying 11 enzymes, found 61 enzyme-deficiency variants in 26,634 determinations (2.3 variants/1000 determinations) for an enzyme-deficiency-allele frequency of 0.00131 . Mohrenweiser and Neel (1984) detected 11 enzyme-deficiency variants in 6741 determinations (1.6 variants/1000 determinations) among samples from several Amerindian tribes. Combining these data with the two data bases from this study, one obtains an overall unweighted mean frequency of 0.00396 for enzyme-deficiency alleles for the five populations.

The apparent differences among ethnic or geographical groups in the frequency of enzyme-deficiency variants reflect, at least in part, differences in the battery of loci studied in the different populations (low figure for Germany), but they also suggest possible ethnic differences (high value for U.S. Blacks). The frequencies observed in the study in Germany are similar to the frequencies at the same loci in the other populations, with the exception of the TPI deficiency in Blacks. The higher frequency of deficiency variants among Blacks is similar to a higher frequency of mobility variants observed in this same population (Neel and Mohrenweiser 1987; Mohrenweiser et al., in preparation). The distribution of deficiency variants (excluding $\mathrm{G}^{2} \mathrm{PDA}^{-}$) among loci is similar in the Black and Caucasian groups with G6PD, TPI, and PK accounting for $70 \%$ and $60 \%$ of the variants. The estimates of the frequency of enzyme-deficiency variants are not inconsis- 
tent with estimated frequencies obtained for other loci from other studies (Martin 1983; Gershowitz 1983).

Similar null-variant frequencies have also been observed in other species. Voelker et al. (1980a) and Langley et al. (1981) have reported frequencies of 2.6 and 2.3 null variants $/ 1000$ determinations in two natural populations of Drosophila melanogaster. Bulfield et al. (1984) identified 3.69 low-activity variants 1000 determinations in screening wild-caught mice (Mus musculus).

Results from several experiments suggest that de novo mutations associated with enzyme deficiency are at least as frequent as mobility mutants. In a study of the spontaneous mutation rate in Drosophila, null mutants occurred at a rate at least three times the rate for mobility mutants (Mukai and Cockerham 1977; Voelker et al. 1980b). Null mutants have been detected with a frequency similar to that of electrophoretic mobility mutants in the offspring of mice exposed to chemical mutagens (Lewis and Johnson 1983, 1986; Charles and Pretsch 1987). The exception to this generalization, of an approximately equal frequency of null and mobility mutants, is the results from two radiation mutagenesis studies in mice, where all seven of the mutations were nulls (Malling and Valcovic 1977; Charles and Pretsch 1986). Racine et al. (1980) also reported an increased null-mutation frequency in the progeny of irradiated Drosophila.

The biochemical basis for the deficiency variants will generally be either (a) the absence of a protein, (b) the presence of a nonfunctional enzyme, or (c) the altered stability of the enzyme. As the erythrocyte is unable to synthesize protein, the reduced stability of an enzyme molecule is a significant cause of erythrocyte enzymopathies although it does not often cause a significant metabolic block in nucleated cells.

The molecular basis for the null variants can range from deletion of the entire allele through single base deletions, which could result in removal of important regulatory sequences and mRNA processing sites to frameshifts. They could also result from point mutations that alter regulatory sequences or processing sites or result in amino acid substitutions causing enzyme instability, inappropriate processing, or the synthesis of a nonfunctional enzyme molecule (Mohrenweiser 1983). This spectrum of events that can give rise to enzyme-deficiency variants contrasts with the situation for mobility variants, which are almost exclusively associated with nucleotide substitutions in exons, which therefore give rise to the interchange of amino acids with nonidentical charge.

Assuming that this estimate of the enzyme-deficiency allele frequency is typical of the average for the remainder of the human genome, one can begin to estimate the total level of hemizygosity. With a deficiency-allele frequency of 0.00396 , the frequency of homozygosity at any locus is $1.56 \times 10^{-5}$. Estimates of the number of loci in the human genome generally range from 50 to 100,000 . Thus, each individual could be hemizygous at 200-400 loci in addition to loci located on the $\mathrm{X}$ chromosome. Assuming that 5000 of these autosomal loci are critical for codominantly inherited traits, such that the absence of a functional gene product is associated with disease, then each conceptuses would be hemizygous at 20 critical loci. With these same assumptions, $7 \%$ of conceptions would be homozygous at a critical locus. It is possible that $5 \%-10 \%$ of the spontaneous abortions [estimated at $50 \%$ of conceptions (Edmonds et al. 1982; Miller et al. 1980) and 30\% of the recognized spontaneous abortions being due to detectable chromosomal anomalies] could be associated with homozygosity for functionally significant enzyme-deficiency variants. This fetal loss plus the diseases associated with single-gene defects constitute a significant health burden for the human population (Neel 1979). Additionally, this background level of hemizygosity increases the potential health burden of new mutations. A portion of the de novo null mutations will exhibit characteristics of a dominant trait since a single event at a locus that is constitutively hemizygous will be manifested in the first generation (Mohrenweiser 1983; Searle and Edwards 1986). This contrasts with the usual expectation that "point" or "gene" mutations will only have heterozygous and limited genetic health consequences for many generations (Denniston 1982; Carter 1982).

Acknowledgement. This work was supported by Department of Energy contract DE-AC02-82ER-60089. The technical assistance and helpful discussions of many individuals are gratefully acknowledged, especially the assistance of S. Fielek and the discussions with J.V.Neel

\section{References}

Albery WJ, Knowles JR (1976) Evolution of enzyme function and the development of catalytic efficiency. Biochemistry $15: 5631-5640$

Bell GI, Pictet R, Rutter WJ (1980) Analysis of the regions flanking the human insulin gene and sequence of an Alu family member. Nucleic Acids Res 8:4091-4109

Beutler E (1978) Hemolytic anemia in disorders of red cell metabolism. Plenum Press, New York

Beutler E (1979) Red cell enzyme defects as nondiseases and diseases. Blood 54:1-7

Bulfield G, Hall JM, Tsakas S (1984) Incidence of inherited enzyme activity variants in feral mouse populations. Biochem Genet 22 : $133-138$

Busslinger M, Moschonas N, Flavell RS (1981) $\beta^{+}$Thalassemia: aberrant splicing results from a single point mutation in an intron. Cell 27:289-298

Carter CO (1977) The relative contribution of mutant genes and chromosome abnormalities to genetic ill-health in man. In: Scott D, Bridges BA, Sobels FH (eds) Progress in genetic toxicology, Elsevier/North Holland, Amsterdam New York

Carter CO (1982) Contribution of gene mutations to genetic disease in humans. Prog Mutat Res 3:1-8

Cavenee WK, Koufos A, Hansen MF (1986) Recessive mutant genes predisposing to human cancer. Mutat Res 168:3-14

Charles DJ, Pretsch W (1986) Enzyme-activity mutations detected in mice after paternal fractionated irradiation. Mutat Res 160:243248

Charles DJ, Pretsch W (1987) Linear dose-response relationship of erythrocyte enzyme-activity mutations in offspring of ethylnitrosourea-treated mice. Mutat Res 176:81-91

Costa T, Scriver CR, Childs B (1985) The effect of Mendelian disease on human health. A measurement. Am J Med Genet 21 :231-242

Daar IO, Artymiuk PJ, Phillip DC, Maquat LE (1986) Human triosephosphate isomerase deficiency: a single amino acid substitution results in a thermolabile enzyme. Proc Natl Acad Sci USA 83: 7903-7907

Denniston C (1982) Low level radiation and genetic risk estimation in man. Annu Rev Genet 16:329-355

Eber SW, Dunnwald M, Heinemann G, Hofstatter T, Weinmann HM, Belohradsky BH (1984) Prevalence of partial deficiency of red cell triosephosphate isomerase in Germany - a study of 3000 people. Hum Genet 67:336-339

Edmonds DK, Lindsay KS, Miller JF, Williamson E, Wood PJ (1982) Early embryonic mortality in women. Fertil Steril 38:447-453

Erickson JM, Schmickel RD (1985) A molecular basis for discrete size variation in human ribosomal DNA. Am J Hum Genet 37:311325 
Fielek S, Mohrenweiser HW (1979) Erythrocyte enzyme deficiencies assessed with a miniature centrifugal analyzer. Clin Chem 25: 384-388

Gershowitz H (1983) Discussion of: Consideration of "silent genes" in the statistical evaluation of blood group findings in paternity testing. In: Walker RH (ed) Inclusion probabilities in parentage testing. American Association of Blood Banks, Arlington, pp 250254

Jeffreys AJ, Wilson V, Thein SL (1985) Hypervariable "minisatellite" regions in human DNA. Nature 314:67-73

Kahn A, Kaplan JC, Dreyfus JC (1979) Advances in hereditary red cell anomalies. Hum Genet 51:1-27

Krietsch WKG, Krietsch H, Kaiser W, Dunnwald M, Kuntz GWK, Duhm J, Bucher T (1977) Hereditary deficiency of phosphoglycerate kinase: a new variant in erythrocytes, not associated with haemolytic anemia. Eur J Clin Invest 7:427-435

Langley CH, Voelker RA, Leigh Brown AJ, Ohnishi S, Dickson B, Montgomery E (1981) Null allele frequency at allozyme loci in natural populations of Drosophila melanogaster. Genetics 99: $151-156$

Lewis SE, Johnson FM (1983) Dominant and recessive effects of electrophoretically detected specific locus mutations. Environ Sci Res 28:267-278

Lewis SE, Johnson FM (1986) The nature of spontaneous and induced electrophoretically detected mutations in the mouse. In: Ramel C, Lambert B, Magnusson J (eds) Genetic toxicology of environmental chemicals, part B: genetic effects and applied mutagenesis. Liss, New York, pp 359-365

Malling HV, Valcovic LF (1977) Biochemical specific locus mutation system in mice. Arch Toxicol 38:45-51

Maquat LE, Chilcote R, Ryan PM (1985) Human triosephosphate isomerase cDNA and protein structure. J Biol Chem 260:37483753

Martin W (1983) Consideration of "silent genes" in the statistical evaluation of blood group findings in paternity testing. In: Walker $\mathrm{RH}$ (ed) Inclusion probabilities in parentage testing. American Association of Blood Banks, Arlington, pp 245-250

Miller JF, Williamson E, Glue J, Gordon YB, Grudzinskas JC, Sykes A (1980) Fetal loss after implantation: a prospective study. Lancet II :554-556

Mohrenweiser HW (1981) Frequency of enzyme deficiency variants in erythrocytes of newborn infants. Proc Natl Acad Sci USA 78: $5046-5050$

Mohrenweiser HW (1983) Enzyme deficiency variants: frequency and potential significance in human populations. Isozymes Curr Top Biol Med Res 10:51-68

Mohrenweiser HW, Fielek S (1982) Elevated frequency of carriers for triosephosphate isomerase deficiency in newborn infants. Pediatr Res 16:960-963

Mohrenweiser HW, Neel JV (1984) A "disproportion" between the frequency of rare electromorphs and enzyme deficiency variants in Amerindians. Am J Hum Genet 36: 655-662

Mohrenweiser HW, Novotny JE (1982) An enzymatically inactive variant of human lactate dehydrogenase - LDHB*GUA-1: study of subunit interaction. Biochim Biophys Acta 702:90-98

Mohrenweiser HW, Fielek S, Wurzinger KH (1981) Characteristics of enzymes of erythrocytes from newborn infants and adults. Activity, thermostability and electrophoretic profile as a function of cell age. Am J Hematol 11:125-136

Mohrenweiser HW, Wurzinger KH, Neel JV (1987) Frequency and distribution of rare electrophoretic mobility variants in a human population. Ann Hum Genet (in press)

Monaco AP, Neve RL, Colletti-Feener C, Bertelson CJ, Kurmit DM, Kunkel LM (1986) Isolation of candidate cDNAs for portions of the Duchenne muscular dystrophy gene. Nature 323:646-650

Motulsky AG, Yoshida A (1969) Methods for the study of red cell glucose-6-phosphate dehydrogenase. In: Yunis JJ (ed) Biochemical methods in red cell genetics. Academic Press, New York London, pp 51-91
Mukai T, Cockerham CC (1977) Spontaneous mutation rates at enzyme loci in Drosophila melanogaster. Proc Natl Acad Sci USA $74: 2514-2517$

Neel JV (1979) The contribution of germinal mutation to human disease. Am J Med 66:902-903

Neel JV, Mohrenweiser HW (1984) Failure to demonstrate mutations affecting protein structure or function in children with congenital defects or born prematurely. Proc Nat1 Acad Sci USA 81:54995503

Neel JV, Mohrenweiser HW, Satoh C, Hamilton HB (1979) A consideration of two biochemical approaches to monitoring human populations for a change in germ cell mutations rates. In: Barg $\mathrm{K}$ (ed) Genetic damage in man caused by environmental agents. Academic Press, New York London, p 29

Neel JV, Mohrenweiser HW, Gershowitz H (1987) A pilot study of the use of placental cord blood samples in monitoring for mutational events. Mutat Res (in press)

Office of Technology Assessment (1986) Technology for detecting heritable mutations in human beings. US Government Printing Office, Washington, DC

Racine RR, Langley CH, Voelker RA (1980) Enzyme mutants induced by low-dose-rate $\gamma$-irradiation in Drosophila: frequency and characterization. Environ Mutagen 2:167-177

Rosa R, Prehu M-O, Calvin M-C, Badoual J, Alix D, Girod R (1985) Hereditary triosephosphate isomerase deficiency: seven new homozygous cases. Hum Genet 71:235-240

Rotwein PS, Chirgwin J, Province M, Knowler WC, Pettitt DJ, Cordell B, Goodman HM, Permutt MA (1983) Polymorphism in the 5 flanking region of the human insulin gene: a genetic marker for non-insulin-dependent diabetes. N Engl J Med 308:65-71

Rozen R, Fox J, Fenton WA, Horwich AL, Rosenberg LE (1985) Gene deletion and restriction fragment length polymorphisms at the human ornithine transcarbomylase locus. Nature 313:815-817

Satoh C, Neel JV, Yamashita A, Goriki K, Fujita M, Hamilton HB (1983) The frequency among Japanese of heterozygotes for deficiency variants of 11 enzymes. Am J Hum Genet 35:656-674

Searle AG, Edwards JH (1986) The estimation of risks from the induction of recessive mutations after exposure to ionising radiation. J Med Genet 23:220-226

Seizinger BR, Martuga RL, Gusella JF (1986) Loss of genes on chromosome 22 in tumorigenesis of human acoustic neuroma. Nature 322:644-647

Spritz RA, Forget BG (1983) The thalassemias: molecular mechanisms of human genetic disease. Am J Hum Genet 35:333-361

Spritz FA, Jagadeeswaran P, Choudary PV, Biro PA, Elder JT, deRiel JK, Manley JL, Gefter ML, Forget BG, Weismann SM (1981) Base substitution in an intervening sequence of a $\beta^{+}$-thalassemic human globin gene. Proc Natl Acad Sci USA 78:2455-2459

Tanis RJ, Neel JV, DeArauz TR (1977) Two more "private" polymorphisms of Amerindian tribes: LDH GUA-1 and ACP B GUA-1 in the Guaymi of Panama. Am J Hum Genet 29:419-430

Voelker RA, Langley $\mathrm{CH}$, Brown AJL, Ohniski S, Dickson B, Montgomery E, Smith SC (1980a) Enzyme null alleles in natural populations of Drosophila melanogaster: frequencies in a North Carolina population. Proc Natl Acad Sci USA 77 :1091-1095

Voelker RA, Schaffer HE, Mukai T (1980b) Spontaneous allozyme mutations in Drosophila: rate of occurrence and nature of the mutants. Genetics 94:961-968

Vogel F (1984) Clinical consequences of heterozygosity for autosomal-recessive diseases. Clin Genet 25:381-415

Yang TP, Patel PI, Chinault AC, Stout JT, Jackson LG, Hildebrand BM, Caskey CT (1984) Molecular evidence for new mutations at the hprt locus in Lesch-Nyhan patients. Nature 310:412-414

Received February 18, 1987 / Revised May 18, 1987 